\title{
Exploiting phenotype diversity in a local animal genetic resource: identification of a single nucleotide polymorphism associated with the tail shape phenotype in the autochthonous Casertana pig breed
}

Bertolini, Francesca; Schiavo, Giuseppina; Tinarelli, Silvia; Santoro, Laura; Utzeri, Valerio Joe; Dall'Olio, Stefania; Costa, Leonardo Nanni; Gallo, Maurizio; Fontanesi, Luca

Published in:

Livestock Science

Link to article, DOI:

10.1016/j.livsci.2018.08.007

Publication date:

2018

Document Version

Peer reviewed version

Link back to DTU Orbit

Citation (APA):

Bertolini, F., Schiavo, G., Tinarelli, S., Santoro, L., Utzeri, V. J., Dall'Olio, S., Costa, L. N., Gallo, M., \&

Fontanesi, L. (2018). Exploiting phenotype diversity in a local animal genetic resource: identification of a single nucleotide polymorphism associated with the tail shape phenotype in the autochthonous Casertana pig breed. Livestock Science, 216, 148-152. https://doi.org/10.1016/j.livsci.2018.08.007

\section{General rights}

Copyright and moral rights for the publications made accessible in the public portal are retained by the authors and/or other copyright owners and it is a condition of accessing publications that users recognise and abide by the legal requirements associated with these rights.

- Users may download and print one copy of any publication from the public portal for the purpose of private study or research.

- You may not further distribute the material or use it for any profit-making activity or commercial gain

- You may freely distribute the URL identifying the publication in the public portal 


\section{Accepted Manuscript}

Exploiting phenotype diversity in a local animal genetic resource: identification of a single nucleotide polymorphism associated with the tail shape phenotype in the autochthonous Casertana pig breed

Francesca Bertolini, Giuseppina Schiavo, Silvia Tinarelli , Laura Santoro, Valerio Joe Utzeri, Stefania Dall'Olio , Leonardo Nanni Costa , Maurizio Gallo , Luca Fontanesi

PII: S1871-1413(18)30234-8

DOI: https://doi.org/10.1016/j.livsci.2018.08.007

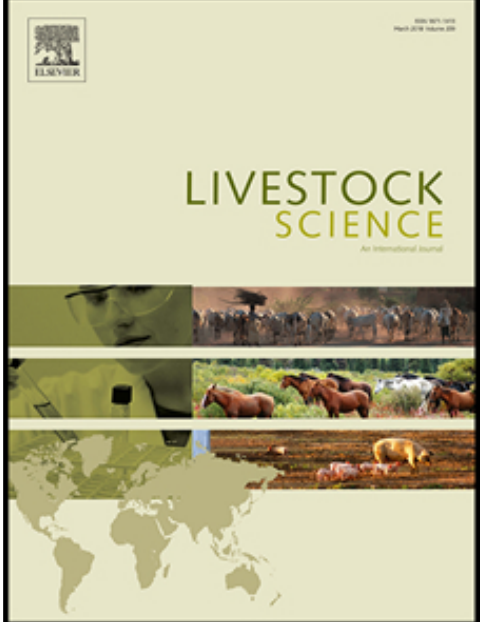

Reference: LIVSCI 3513

To appear in:

Livestock Science

Received date: 22 February 2018

Revised date: $\quad 9$ August 2018

Accepted date: 13 August 2018

Please cite this article as: Francesca Bertolini, Giuseppina Schiavo, Silvia Tinarelli , Laura Santoro, Valerio Joe Utzeri , Stefania Dall'Olio, Leonardo Nanni Costa, Maurizio Gallo, Luca Fontanesi, Exploiting phenotype diversity in a local animal genetic resource: identification of a single nucleotide polymorphism associated with the tail shape phenotype in the autochthonous Casertana pig breed, Livestock Science (2018), doi: https://doi.org/10.1016/j.livsci.2018.08.007

This is a PDF file of an unedited manuscript that has been accepted for publication. As a service to our customers we are providing this early version of the manuscript. The manuscript will undergo copyediting, typesetting, and review of the resulting proof before it is published in its final form. Please note that during the production process errors may be discovered which could affect the content, and all legal disclaimers that apply to the journal pertain. 


\section{Highlights}

- Casertana is an autochthonous pig genetic resource reared in Central-South of Italy.

- Tail shape phenotype variability in the breed was investigated in a GWAS.

- A single nucleotide polymorphism on porcine chromosome 12 was associated with this trait.

- This marker is close to the SRY-box 9 (SOX9) gene that is essential in skeletogenesis.

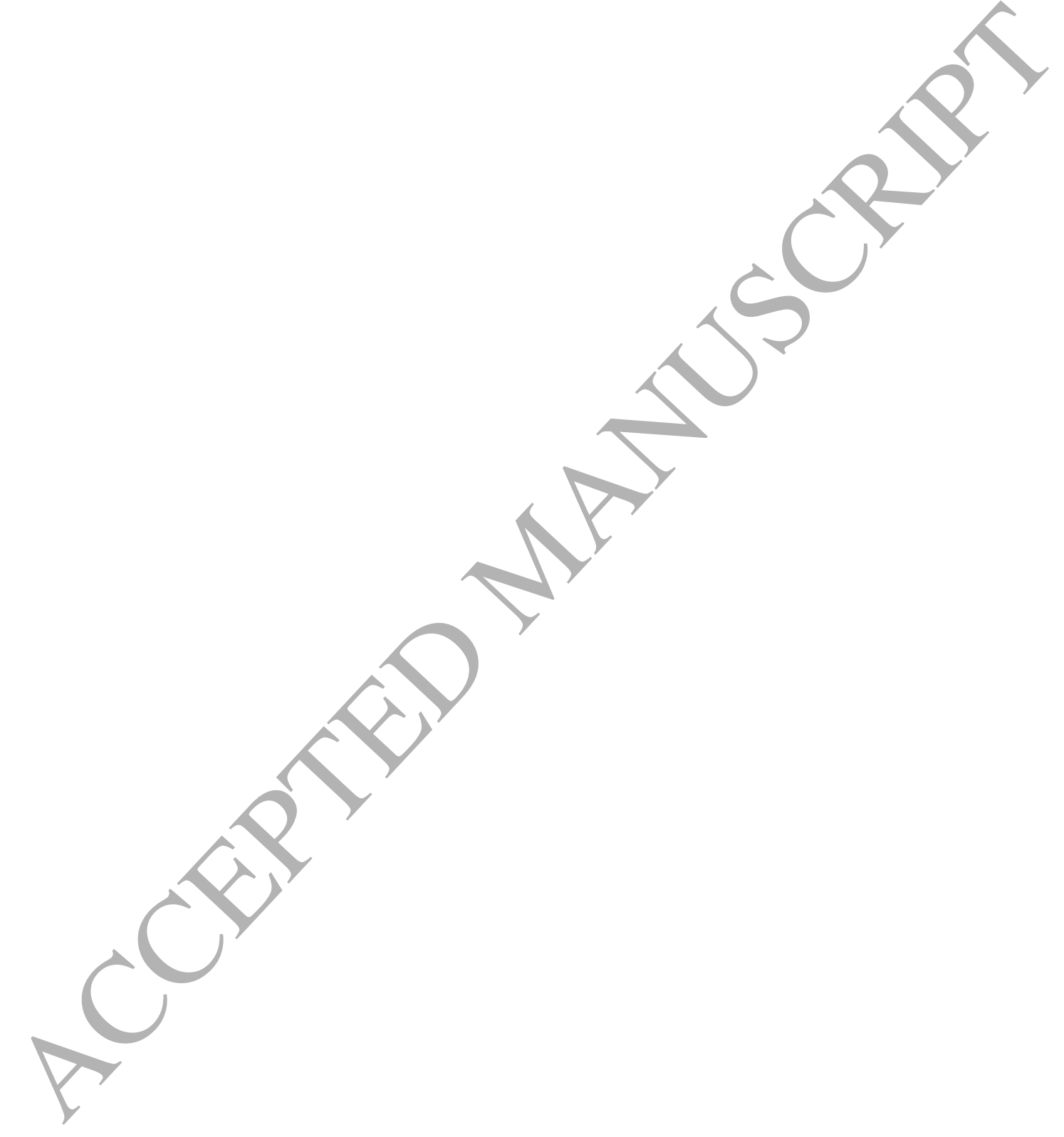


Exploiting phenotype diversity in a local animal genetic resource: identification of a single nucleotide polymorphism associated with the tail shape phenotype in the autochthonous Casertana pig breed

Francesca Bertolini ${ }^{1,2, *}$, Giuseppina Schiavo ${ }^{1, *}$, Silvia Tinarelli ${ }^{1,3}$, Laura Santoro ${ }^{4}$, Valerio Joe Utzeri $^{1}$, Stefania Dall'Olio ${ }^{1}$, Leonardo Nanni Costa ${ }^{1}$, Maurizio Gallo ${ }^{3}$ and Luca Fontanesi ${ }^{1}$

${ }^{1}$ Department of Agricultural and Food Sciences, Division of Animal Sciences, University of Bologna, Viale Fanin 46, 40127 Bologna, Italy

${ }^{2}$ Department of Bio and Health Informatics, Technical University of Denmark, Kemitorvet, 2800 Kgs. Lyngby, Denmark

${ }^{3}$ Associazione Nazionale Allevatori Suini, Via L. Spallanzani 4, 00161 Roma, Italy

${ }^{4}$ ConSDABI - National Focal Point Italiano FAO, Contrada Piano Cappelle, 82100 Benevento, Italy

Corresponding author: Luca Fontanesi, e-mail: luca.fontanesi@unibo.it

* These authors contributed equally to this work.

Running title: SNPs and tail shape phenotype in pigs 


\section{Abstract}

Casertana is a local pig breed mainly raised in Central-South regions of Italy. Pigs of this breed are considered the descendants of the ancient Neapolitan population that largely influenced the constitution of the modern commercial pigs. The pigs of this breed are usually curly-tailed, like several other domestic pig populations. However, Casertana population shows some variability for this trait, including animals having straight tail as observed in wild boars. In this study, we run, for the first time, a genome wide association study (GWAS) comparing the curly tailed $($ no. $=53)$ and straight tailed (no. = 19) Casertana pigs to identify genomic regions associated with the tail shape phenotype in Sus scrofa. All animals were genotyped with the Illumina PorcineSNP60 BeadChip v.2. GEMMA software was used in the GWAS for which we were able to correct for stratification in the analysed cohort. A single nucleotide polymorphism (rs81439488), located on porcine chromosome 12 , was significantly associated with the investigated trait. This marker is close to the SRY-box 9 (SOX9) gene that encodes for a transcription factor that is required during sequential steps of the chondrocyte differentiation pathway, notochord maintenance and skeletogenesis. As the shape of the tail could be important in relation to the problem of tail biting in pigs, the obtained results might open new perspectives for defining selection programs answering indirectly animal welfare issues. This work demonstrated that autochthonous animal genetic resources might be used to disclose genetic factors affecting peculiar traits by exploiting segregating phenotypes and genetic variability.

Keywords: Animal genetic resource; autochthonous breed; GWAS; morphological trait; SNP; Sus scrofa. 


\section{Introduction}

Conservation of animal genetic resources is mainly aimed to preserve genetic diversity and associated inheritable phenotypes characterizing different populations that might be interesting for current or future purposes, including potential use in breeding programs. These resources can be also useful to understand biological mechanisms determining unique phenotypes derived by diversity in selection pressures or as result of adaptation to environmental and production conditions (Leroy et al., 2016).

Casertana pigs constitute a local breed mainly raised in Central-South regions of Italy. Pigs of this breed are considered the descendants of the ancient Neapolitan pig population that largely influenced the constitution of the modern commercial pig breeds through introgression of blood into British pig populations during the $19^{\text {th }}$ century (Porter, 1993). Neapolitan pigs were, in turn, influenced by Asian blood in the late $18^{\text {th }}$ century (Porter, 1993). Casertana is enlisted among the endangered animal genetic resources as the herd book of this breed accounts for about 100 boars and sows currently registered (ANAS, 2016). Animals are mainly raised in extensive or semiextensive production systems with possible contacts and crossbreeding with European wild boars that could have contributed, at least in part, to shape their morphological characteristics. Casertana pigs have a black or grey coat colour, wrinkled skin, forward ears, and usually a typical hairless phenotype. The pigs of this breed are usually curly-tailed, like several other domestic pig populations. However, Casertana population shows some variability for this trait, including animals having straight and wavy tail as in a few other pig breeds and in wild boars.

Domestication in mammals has been a complex and continuous process associated with a series of changes in the domesticated animals compared to the wild counterparts, derived by selective breeding of animals showing favourable production and reproduction performances, and increased docility that indirectly shaped the genome of domesticated populations (Wiener and Wilkinson, 2011; Larson and Burger, 2013; Carneiro et al., 2014; Wang et al., 2014; Wilkins et al., 2014). Several morphological features have been also directly or indirectly selected and, in most 
cases, fixed in domesticated populations as result of the domestication process (Darwin, 1868). Coat colour is one of the most common phenotypic traits that has been modified as result of reduced selective pressure against colours with low fitness in the wild and of aesthetic preferences of the breeders, sometimes associated with higher production performances (Clutton-Brock, 1999). Among several other morphological characters, curliness of the tail and shape has been associated with domestication in mammals (Trut et al., 2009).

The tail is considered an extension of the spinal column usually composed of specifically shaped vertebrae. Spontaneous curly tail phenotypes in mice have been the matter of studies that investigated the role of embryonic development in this morphological anomaly (Copp et al., 1988; van Straaten and Copp, 2001; Ohnishi et al., 2017). Curly tail is also commonly observed in many dog breeds. Vaysse et al. (2011) compared the genome of dog breeds having curly tails with that of breeds with straight tails using single nucleotide polymorphisms (SNPs) chip data and identified a genomic region on chromosome 1 significantly associated with these alternative tail shapes.

In pigs, few studies have been reported on the genetic factors affecting tail shape. A putative recessive genetic defect known as kinky tail (or flexed or screw tail), derived by fused caudal vertebrae associated in some cases with other defects, has been described in the mid of the last century (Nordby, 1934; Donald, 1949; Brooksbank, 1958). It is not known if this defect could be, in some way, related or not to the normal curling of the tail that is common in domestic pigs. This signature of domestication, however, seems not fixed in all pig breeds (Porter, 1993) but no systematic study, has been conducted so far, probably because the difficulties in retrieving phenotype information due to the usual practice of tail docking in most herds.

In this study, we took advantage from the variability of the shape of the tail that we recorded in the Casertana pig population and run a genome wide association study (GWAS) comparing the genome of curly-tailed and straight tailed animals to identify genomic regions associated with the tail shape phenotype in Sus scrofa. 


\section{Materials and methods}

\subsection{Animals}

A total of 101 Casertana pigs (of about 7 to 20 months old) from six different farms were evaluated. Photographic records of each animal were obtained to capture information on the tail shape in standardized restraining conditions (including a direct evaluation of the personnel on this phenotype during this phase for the biological sampling) for all animals and after release (Figure 1). Pigs were classified as follows: 53 (25 males and 28 females) showed the curly tail phenotype; 19 (five males and 14 females) showed the straight tail phenotype; 29 were not classified and excluded from the study as tail docking, that was practised by the farmers as routine before weaning of the piglets, prevented the recording of any tail phenotype.

\subsection{Genotyping}

Hairs (with roots) were collected from the investigated pigs. DNA extraction was carried out using the Wizard ${ }^{\circledR}$ Genomic DNA Purification kit (Promega Corporation, Madison, WI, USA) following the manufacturer's instructions. Genotyping of the extracted DNA was obtained with the Illumina PorcineSNP60 BeadChip v.2 (Illumina, Inc., San Diego, CA, USA) that interrogated 61,565 SNPs. Single nucleotide polymorphisms were assigned to the Sscrofa11.1 genome version, as previously described (Fontanesi et al., 2012). PLINK 1.9 software (Chang et al., 2015) was used to filter SNPs and genotyping data using the following criteria already used in a similar study (Schiavo et al., 2018): genotyping call rate $>0.9$, minor allele frequency $>0.01$ and Hardy-Weinberg equilibrium $P>0.001$.

\subsection{Data analysis and genome wide association}

To evaluate distance relationships among the animals of the investigated cohort, multidimensional scaling (MDS) was obtained with the PLINK 1.9 software (Chang et al., 2015). Genome wide association study was carried out by applying the univariate mixed model of 
GEMMA (Zhou and Stephens, 2012) that can accommodate the centered relatedness matrix calculated from SNP genotypes to correct for population stratification in a case and control analysis. The model also included the farm and the sex as fixed effects. To be able to identify associated markers in this experiment that included a low number of animals (derived by the fact that the analysed pigs were almost a complete representation of the whole population of the Casertana breed) and that used a SNP chip that might originally have an ascertain bias (as local breeds were not used for the selection of the informative SNPs), the significant threshold was defined at the $P_{\text {nominal value }}<5.00 \mathrm{E}-05$ level, according to the Wellcome Trust Case Control Consortium (2007) and as also applied in several other GWAS in livestock (e.g. Fontanesi et al., 2012; Sanchez et al., 2014). Genomic inflation factor $(\lambda)$ and quantile-quantile $(Q-Q)$ plot were obtained with GenABEL (Aulchenko et al., 2007). Gene annotation information was retrieyed from the Sscrofa11.1 genome version available at the Ensembl database (http://www.ensembl.org/Sus_scrofa/Info/Index), release 91.

\section{Results and discussion}

A recent phenotypic characterization of the endangered Casertana pig population that we carried out noted several morphological differences among distinct animals of this autochthonous breed (data not shown). For example, in addition to the hairless or hypotrichotic condition (that is the characteristic phenotype of the Casertana animals), we already described the presence of haired pigs in this population and this morphological variability was used for a GWAS that we have recently reported (Schiavo et al. 2018). Despite a limited number of animals was included in that study, we were able to identify genomic regions associated with the hairless phenotype, demonstrating that local animal genetic resources can be used to genetically describe phenotypic variability of simple traits (Schiavo et al., 2018).

Another morphological trait that is not fixed in this breed is the shape of the tail (Figure 1). Of the animals for which we could record this phenotype, 26\% (19 out of 72) showed a straight tail 
without any curls, similarly to the usual shape of wild boars. This shape was clearly different from the curly tails reported in the remaining investigated pigs (74\%). There was no age effect and the two groups included a comparable number of males and females so that sex did not explain the tail shape phenotype. In addition, we could exclude the possible effect of the behavioral change of tail posture on this phenotype (Zonderland et al., 2009). The recording system was based on standardized conditions and subsequent photographic records of the animals confirmed, at least for the photographic time point, their assignment to one or to the other group of tail shape phenotype. The two groups were observed in animals from all six farms. Limited pedigree record prevented the possibility to evaluate any potential founder effect.

A total of 36,533 autosomal SNPs, mapped to a unique position in the Sscrofa11.1 genome version, was used for MDS. The obtained MDS plot showed some structures not well defined in the analysed pigs that however did not clearly separate the curly and straight tailed Casertana pigs (Figure 2). A stratified sample could be a critical point in GWAS in a very small population where, to some extent, all animals might be related. Figure S1 reports the genomic inflation factor $(\lambda)$ and Q-Q plot that did not show any biased test statistic distribution, suggesting that the investigated cohort was corrected for a possible stratification effect.

Figure 3 reports the Manhattan plot obtained in this GWAS. One significant SNP (P=2.3E-05) was identified on porcine chromosome 12 (SSC12). This marker indicated as ALGA0064877 (rs81439488 C/A) is located at position 10,301,075 of this chromosome. Allele A of this SNP was more frequent in the straight tail group (0.17) than in the curly tailed group (0.03).

The complete list of genes annotated around the ALGA0064877 marker (with known functions) is reported in Table S1. Figure S2 report a screenshot of this SSC12 region retrieved from ENSEMBL database with the annotated genes. One of the closest gene in this desert chromosome region is the SRY-box 9 (SOX9) gene (positions 8,641,629-8,647,764, encoded by the 1 strand; actually the closest upstream gene to the significant SNP), that, according to its function, might be the most plausible candidate gene, explaining the recorded phenotypic variability. It is 
well established that the expression of this gene at the embryonal level marks the onset of cartilage differentiation (Wright et al., 1995; Healy et al., 1996). SOX9 encodes for a transcription factor that is required during sequential steps of the chondrocyte differentiation pathway, notochord maintenance and skeletogenesis (Akiyama et al., 2002; Barrionuevo et al., 2006; Montero et al., 2017). Continued expression of Sox9 in differentiated chondrocytes is essential for subsequent hypertrophy and sustains chondrocyte-specific survival mechanisms (Ikegami et al., 2011). Although SOX9 seems to be a master gene for chondrocytes differentiation, the whole region surrounding the marker ALGA0064877 is downstream closer to a few genes [i.e. potassium voltage-gated channel subfamily J member 2 (KCNJ2), 61169 bp of distance from the SNP; potassium voltage-gated channel subfamily $\mathrm{J}$ member 16 (KCNJ16), 147461 bp of distance; mitogen-activated protein kinase kinase 6 (MAP2K6), $570407 \mathrm{bp}$ of distance]. Alterations in the genes of this region have been also observed to affect the Wnt pathway (Kurth et al., 2009). Heterozygous mutations within and around human SOX9 cause campomelic dysplasia that is a malformation syndrome characterized by cartilage derived skeletal structure defects (Foster et al., 1994; Wagner et al., 1994). These mutations, most of which reduce the level of expression of this gene, are located upstream spanning a large region (from $50 \mathrm{~kb}$ to more than $1 \mathrm{Mb}$ ) in which regulatory elements are present (Wunderle et al., 1998; Bagheri-Fam et al., 2006). Close upstream mutations produce more severe defects whereas far upstream mutations cause mild defects (Pfeifer et al., 1999; Velagaleti et al., 2005; Leipoldt et al., 2007). About 40 k SNPs, located between SOX9 and MAP2K6, are reported in the Sscrofa11.1 genome version and could be considered for future studies to identify the causative mutation(s). Among them, 20 are also present in the PorcineSNP60 BeadChip but only ALGA0064877 reached the threshold of significance, probably due to the biased chip design that might not be able to capture particular haplotype structures of this breed.

Based on these studies in other species it is tempting to suggest a possible regulatory mechanism affecting SOX9 expression in porcine developing chondrocytes that would, in turn, produce a mild cartilage/skeletal effect determining the shape of the tail. This hypothesis might be 
worth of further investigation starting from a precise characterization of the structure and morphology of the pig tail with different shapes for which, at present, there is no detailed investigation. Our phenotype records were based only on an external morphological evaluation of the shape of the tail. Furthermore, analysis of gene expression of SOX9 at different developmental stages should be also carried out to evaluate the role of this gene in the phenotype observed in pigs.

The results we obtained might have broader impacts than those that would be limited to a simple morphological characterization. The shape of the tail could be important in relation to the problem of tail biting in pigs. Tail biting is a widespread behavioral vice with significant animal welfare implications and economic losses in commercial pig farms (Bracke et al., 2004). A few studies have established correlations between tail posture and tail biting incidence suggesting limited damages and related welfare complications with behaviors of the pigs that tended to have a tail posture up that those with tail posture down (Zonderland et al., 2009; Lahrmann et al., 2018). It would be interesting to evaluate if pigs with genetically determined curly tails (as a possible adaptation derived by the domestication process) are less affected by tail biting damages than pigs with straight tails.

\section{Conclusions}

This work demonstrated that autochthonous animal genetic resources, even constituted by very small populations, might be used to disclose genetic factors affecting peculiar traits by exploiting segregating phenotypes and genetic variability. To our knowledge, this is the first study that reported a frequency distribution of the tail shape phenotype in a pig population. Our results indicated that this morphological trait is associated with a marker close to an important gene involved in embryonic development, opening other hypothesis, worth of further investigations. It will be important to validate the results we obtained in this GWAS in other breeds and populations, including a more precise anatomical characterization of this trait, to further extend the impact of the results reported in Casertana pigs. It would be however first needed to know if diversity for this 
morphological characteristic is common in commercial pig populations as at present, there is not information on this aspect, mainly due to the usual practice of tail docking that prevents the recording of this phenotype. Considering the potential relationship between tail shape and tail biting damages (that, however, remains to be formally demonstrated), it could be possible to envisage practical applications of the identified marker in selection programs aimed to respond to animal welfare issues. From this study it emerges that conservation strategies of autochthonous pig genetic resources should take also into account the preservation of phenotypic variability within populations. Our study represents one of the few examples of exploitation of animal genetic resources to recover information that might have potential impacts in commercial populations.

\section{Acknowledgements}

The Authors thank all farmers and personnel that contributed to collect phenotypes and samples.

\section{Funding}

This work has received funding from the Italian Ministry of Agriculture, Food and Forestry (MiPAAF) under the project INNOVAGEN and from the European Union's Horizon 2020 research and innovation programme under grant agreement No 634476 (Project acronym: TREASURE). The content of this paper reflects only the authors' view and the European Union Agency is not responsible for any use that may be made of the information it contains. This study was associated with the PSRN program (2017-2019).

\section{Conflict of interest statement}

The authors declare that there is no conflict of interest regarding the publication of this paper.

\section{References}


Akiyama, H., Chaboissier, M.C., Martin, J.F., Schedl, A., de Crombrugghe, B. 2002. The transcription factor Sox9 has essential roles in successive steps of the chondrocyte differentiation pathway and is required for expression of Sox 5 and Sox6. Genes Dev. 16, $2813-2828$.

ANAS, 2016. Registro Anagrafico. http://www.anas.it/.

Aulchenko, Y.S., Ripke, S., Isaacs, A., van Duijn C.M., 2007. GenABEL: an R library for genomewide association analysis. Bioinformatics 23, 1294-1296.

Bagheri-Fam, S., Barrionuevo, F., Dohrmann, U., Günther, T., Schüle, R., Kemler, R., Mallo, M., Kanzler, B., Scherer, G. 2006. Long-range upstream and downstream enhancers control distinct subsets of the complex spatiotemporal Sox9 expression pattern. Dev. Biol. 291, 382397.

Barrionuevo, F., Taketo, M. M., Scherer, G., Kispert, A. 2006. Sox9 is required for notochord maintenance in mice. Dev. Biol. 295, 128 140.

Bracke, M.B.M., Hulsegge, B., Keeling, L., Blokhuis, H.J. 2004. Decision support system with semantic model to assess the risk of tail biting in pigs. 1. Modelling. Appl. Anim. Behav. Sci. $87,31-44$.

Brooksbank, N.H. 1958. Congenital deformity of the tail in pigs. Br. Vet. J. 114, 50-55.

Carneiro, M., Rubin,C.J., DiPalma, F., Albert, F.W., Alföldi, J., Martinez Barrio, A., Pielberg, G., Rafati, N., Sayyab, S., Turner-Maier, J., Younis, S., Afonso, S., Aken, B., Alves, J.M., Barrell, D., Bolet, G., Boucher, S., Burbano, H.A., Campos, R., Chang, J.L., Duranthon, V., Fontanesi, L., Garreau, H., Heiman, D., Johnson, J., Mage, R.G., Peng, Z., Queney, G., Rogel-Gaillard, C., Ruffier, M., Searle, S., Villafuerte, R., Xiong, A., Young, S., ForsbergNilsson, K., Good, J.M., Lander, E.S., Ferrand, N., Lindblad-Toh, K., Andersson, L. 2014. Rabbit genome analysis reveals a polygenic basis for phenotypic change during domestication. Science 345, 1074-1079. 
Chang, C.C., Chow, C.C., Tellier, L.C., Vattikuti, S., Purcell, S.M., Lee, J.J. 2015. Secondgeneration PLINK: rising to the challenge of larger and richer datasets. Gigascience 4, 7.

Clutton-Brock, J. 1999. A Natural History of Domesticated Mammals. $2^{\text {nd }}$ Edition, Cambridge, UK: Cambridge University Press.

Copp, A. J., Brook, F. A., \& Roberts, H. J. 1988. A cell-type-specific abnormality of cell proliferation in mutant (curly tail) mouse embryos developing spinal neural tube defects. Development 104, 285-295.

Darwin, C. 1868. The Variation of Animals and Plants under Domestication. London, UK: John Murray.

Donald, H. P., 1949. The inheritance of a tail abnormality associated with urogenital disorders in pigs. J. Agric. Sci. 39, 164-173.

Fontanesi, L., Schiavo, G., Galimberti, G., Calò, D.G., Scotti, E., Martelli, P.L., Buttazzoni, L., Casadio, R., Russo, V. 2012. A genome wide association study for backfat thickness in Italian Large White pigs highlights new regions affecting fat deposition including neuronal genes. BMC Genomics 13, 583.

Foster, J.W., Dominguez-Steglich, M.A., Guioli, S., Kwok, C., Weller, P.A., Stevanović, M., Weissenbach, J., Mansour, S., Young, I.D., Goodfellow, P.N., et al. 1994. Campomelic dysplasia and autosomal sex reversal caused by mutations in an SRY-related gene. Nature $372,525-530$.

Healy, C., Uwanogho, D., Sharpe, P.T. 1996. Expression of the chicken Sox9 gene marks the onset of cartilage differentiation. Ann. N. Y. Acad. Sci. 785, 261-262.

Ikegami, D., Akiyama, H., Suzuki, A., Nakamura, T., Nakano, T., Yoshikawa, H., Tsumaki, N. 2011. Sox9 sustains chondrocyte survival and hypertrophy in part through Pik3ca-Akt pathways. Development 138, 1507-1519.

Kurth, I., Klopocki, E., Stricker, S., van Oosterwijk, J., Vanek, S., Altmann, J., Santos, H.G., van Harssel, J.J., de Ravel, T., Wilkie, A.O., Gal, A., Mundlos, S. 2009 Duplications of 
noncoding elements 5' of SOX9 are associated with brachydactyly-anonychia. Nat. Genet. $41,862-863$.

Lahrmann, H. P., Hansen, C. F., D’Eath, R., Busch, M. E., \& Forkman, B. (2018). Tail posture predicts tail biting outbreaks at pen level in weaner pigs. Appl. Anim. Behav. Sci. 200, 29-35. Larson, G., Burger, J. 2013. A population genetics view of animal domestication. Trends Genet. 29, 197-205.

Leipoldt, M., Erdel, M., Bien-Willner, G.A., Smyk, M., Theurl, M., Yatsenko, S.A., Lupski, J.R., Lane, A.H., Shanske, A.L., Stankiewicz, P., Scherer, G. 2007. Two novel translocation breakpoints upstream of SOX9 define borders of the proximal and distal breakpoint cluster region in campomelic dysplasia. Clin. Genet. 71, 67-75.

Leroy, G., Besbes, B., Boettcher, P., Hoffmann, I., Capitan, A., Baumung, R. 2016. Rare phenotypes in domestic animals: unique resources for multiple applications. Anim. Genet. 47, $141-153$.

Montero, J.A., Lorda-Diez, C.I., Francisco-Morcillo, J., Chimal-Monroy, J., Garcia-Porrero, J.A., Hurle, J.M. 2017. Sox9 expression in Amniotes: Species-specific differences in the formation of digits. Front. Cell Dev. Biol. 5, 23.

Nordby J.E. 1934. Kinky tail in swine. J. Hered. 25, 171-174.

Ohnishi, T., Miura, I., Ohba, H., Shimamoto, C., Iwayama, Y., Wakana, S., Yoshikawa, T. 2017. A spontaneous and novel Pax3 mutant mouse that models Waardenburg syndrome and neural tube defects. Gene $607,16-22$.

Pfeifer,D., Kist, R., Dewar, K., Devon, K., Lander, E.S., Birren, B., Korniszewski, L., Back, E., Scherer, G. 1999. Campomelic dysplasia translocation breakpoints are scattered over $1 \mathrm{Mb}$ proximal to SOX9: evidence for an extended control region. Am. J. Hum. Genet. 65, 111124.

Porter, V. 1993. Pigs: A Handbooks to the Breeds of the World. Cornell University Press, 
Sanchez M.P., Tribout T., Iannuccelli N., Bouffaud, M., Servin, B., Tenghe, A., Dehais, P., Muller, N., Del Schneider, M.P., Mercat, M.J., Rogel-Gaillard, C., Milan, D., Bidanel, J.P., Gilbert, H. 2014. A genome-wide association study of production traits in a commercial population of Large White pigs: evidence of haplotypes affecting meat quality. Genet. Sel. Evol. 46, 12.

Schiavo, G., Bertolini, F., Utzeri, V.J., Ribani, R., Geraci, C., Santoro, L., Óvilo, C., Fernández, A.I., Gallo, M., Fontanesi, L. 2018. Taking advantage from phenotype variability in a local animal genetic resource: identification of genomic regions associated with the hairless phenotype in Casertana pigs. Anim. Genet. 49, 321-325.

Trut, L., Oskina, I., Kharlamova, A. 2009. Animal evolution during domestication: the domesticated fox as a model. Bioessays 31, 349-360.

van Straaten, H. W., Copp, A. J. 2001. Curly tail: a 50-year history of the mouse spina bifida model. Anat. Embryol. 203, 225-238.

Vaysse, A., Ratnakumar, A., Derrien, T., Axelsson, E., Rosengren Pielberg, G., Sigurdsson, S., Fall, T., Seppälä, E.H., Hansen, M.S., Lawley, C.T., Karlsson, E.K.; LUPA Consortium, Bannasch, D., Vilà, C., Lohi, H., Galibert, F., Fredholm, M., Häggström, J., Hedhammar, A., André, C., Lindblad-Toh, K., Hitte, C., Webster, M.T. 2011. Identification of genomic regions associated with phenotypic variation between dog breeds using selection mapping. PLoS Genet. 7, e1002316.

Velagaleti, G.V., Bien-Willner, G.A., Northup, J.K., Lockhart, L.H., Hawkins, J.C., Jalal, S.M., Withers, M., Lupski, J.R., Stankiewicz, P. 2005. Position effects due to chromosome breakpoints that map approximately $900 \mathrm{~Kb}$ upstream and approximately $1.3 \mathrm{Mb}$ downstream of SOX9 in two patients with campomelic dysplasia. Am. J. Hum. Genet. 76, 652-662.

Wagner, T., Wirth, J., Meyer, J., Zabel, B., Held, M., Zimmer, J., Pasantes, J., Bricarelli, F.D., Keutel, J., Hustert, E., Wolf, U., Tommerup, N., Schempp, W., Scherer, G. 1994. Autosomal sex reversal and campomelic dysplasia are caused by mutations in and around the SRYrelated gene SOX9. Cell 79, 1111-1120. 
Wang, G.D., Xie, H.B., Peng, M.S., Irwin, D., Zhang, Y.P. 2014. Domestication genomics: evidence from animals. Annu. Rev. Anim. Biosci. 2, 65-84.

Wiener, P., Wilkinson, S. 2011. Deciphering the genetic basis of animal domestication. Proc. Biol. Sci. 278, 3161-3170.

Wilkins, A. S., Wrangham, R. W., Fitch, W. T. 2014. The "domestication syndrome" in mammals: a unified explanation based on neural crest cell behavior and genetics. Genetics 197, 795-808.

Wright, E., Hargrave, M.R., Christiansen, J., Cooper, L., Kun, J., Evans, T., Gangadharan, U., Greenfield, A., Koopman, P. 1995. The Sry-related gene Sox9 is expressed during chondrogenesis in mouse embryos. Nat. Genet. 9, 15-20.

Wunderle, V.M., Critcher, R., Hastie, N., Goodfellow, P.N., Schedl, A. 1988. Deletion of longrange regulatory elements upstream of SOX9 causes campomelic dysplasia. Proc. Natl. Acad. Sci USA 95, 10649-10654.

Zhou, X., Stephens, M. 2012. Genome-wide efficient mixed-model analysis for association studies. Nat. Genet. 44, 821-824.

Zonderland, J.J., van Riel, J.W., Bracke, M.B.M., Kemp, B., den Hartog, L.A., Spoolder, H.A.M., 2009. Tail posture predicts tail damage among weaned piglets. Appl. Anim. Behav. Sci. 121, $165-170$. 
Figure 1. Tail shape of Casertana pigs: a) curly tail; b) straight tail.

a)

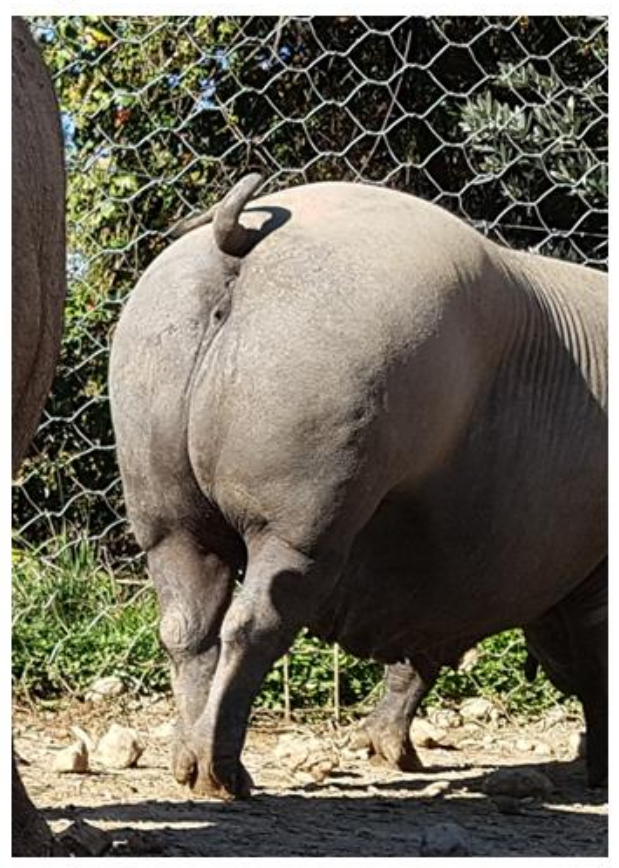

b)

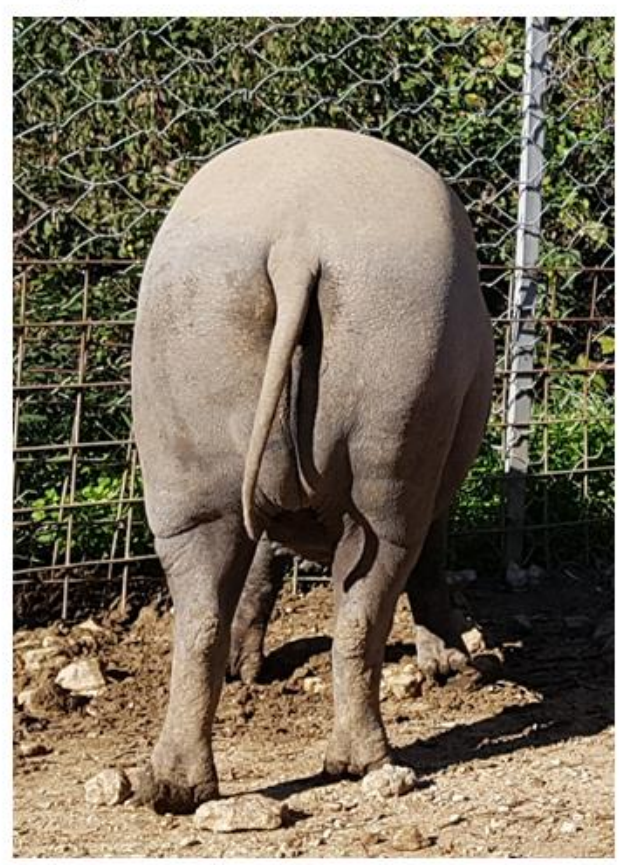

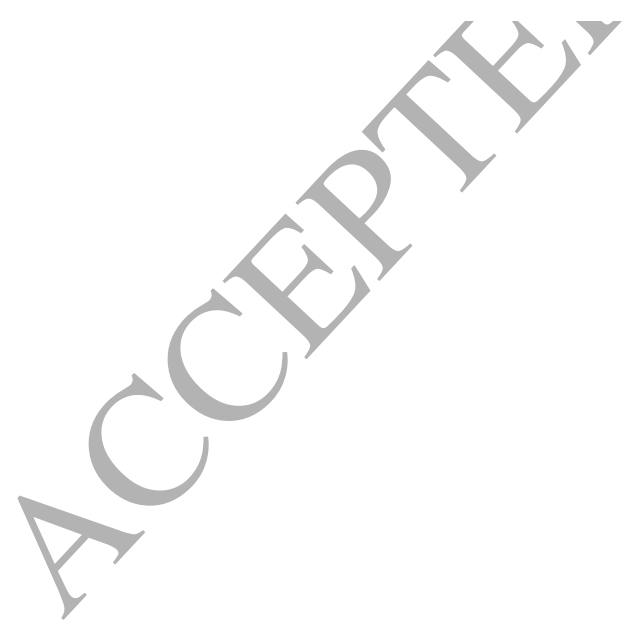


Figure 2. Multidimensional scaling (MDS) with represented the pigs (dots) included in this study divided in the two groups of tail shape.
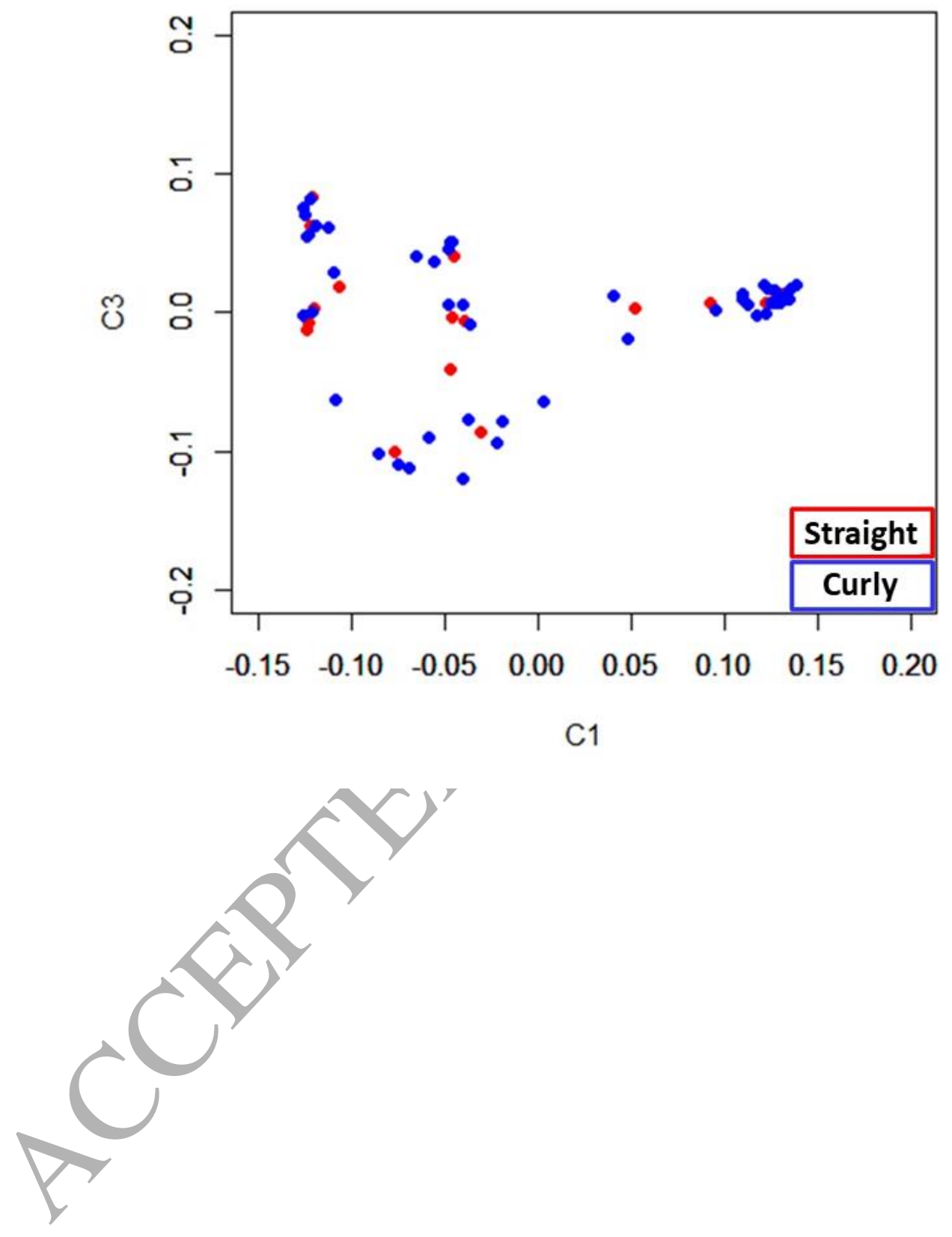
Figure 3. Manhattan plot obtained for the genome wide association study.
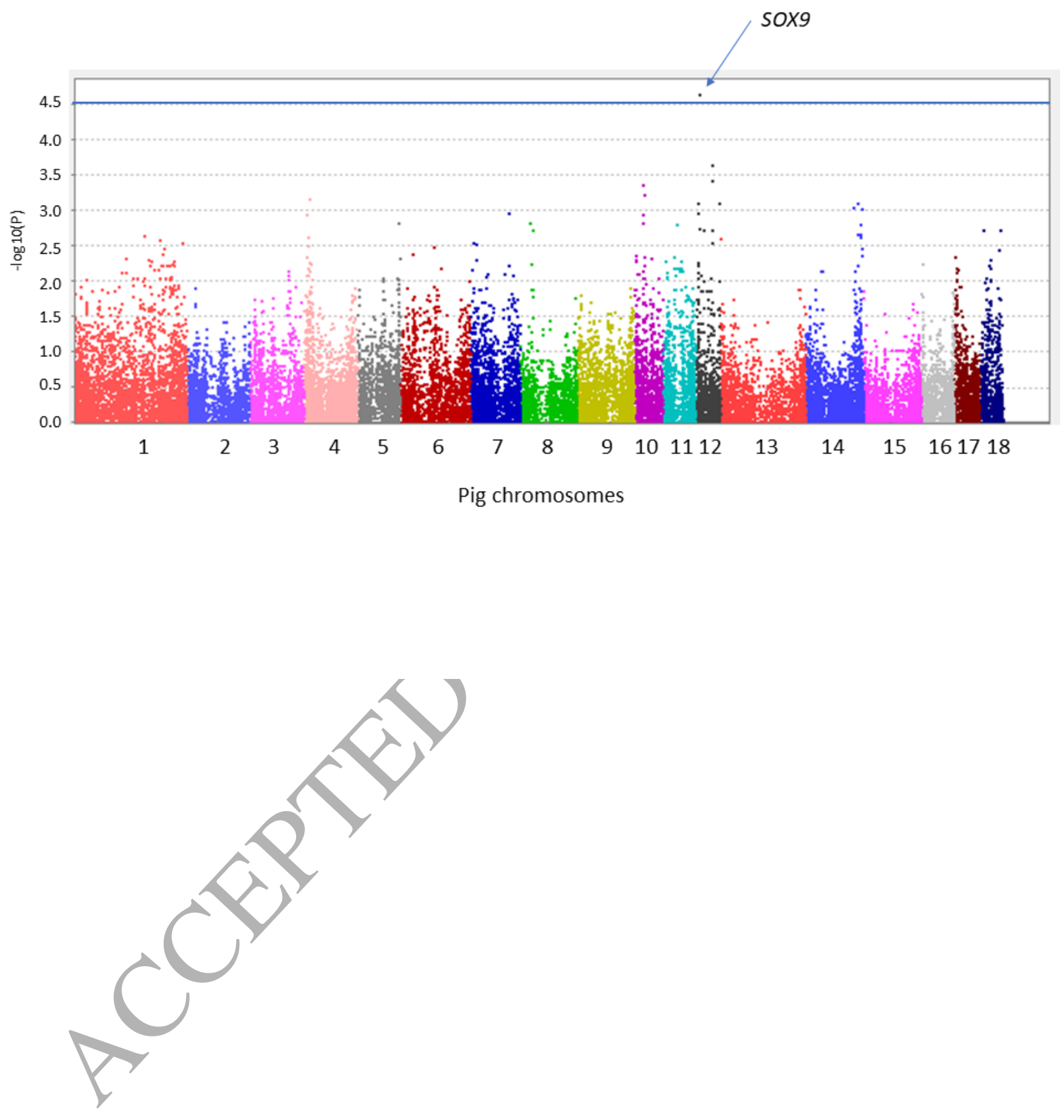